\title{
The Inheritance and Development of Traditional Culture in Interior Design and Three Dimensional Structure
}

\author{
Weiwei Li \\ Institute of environmental art, Hebei Institute of Fine Art, Shijiazhuang, Hebei, 050700, China
}

Keywords: Traditional culture, interior design, inheritance reference

\begin{abstract}
In the modern context, interior design has inevitably become a part of social culture. How to deal with the relationship between interior design and traditional culture, Confucianism, Taoism, Buddhism and other main ideas in traditional culture and its application in interior design are worthy of our thinking. This paper discusses how to link the traditional culture with the modern art design, in order to form an interior design style with the characteristics of traditional culture.
\end{abstract}

\section{The Relationship between Interior Design and Traditional Culture}

Interior design is an organic part of social culture, from the point of view of the horizontal dimension, no matter what kind of style design, have a specific mental and psychological structure of culture is in certain cultural context start and finish, and reflects the different value and aesthetic concepts, reflect the prevailing cultural outlook. From the longitudinal perspective, the design of the interior space of any era is closely related to the productivity and culture at that time. Design form comes from culture, people in accordance with the rich experience (history and tradition) of the processing of all the existing impression. [1] In this sense, the design of history is the history of design.

Traditional culture affects the interior design. Although some modern designers, especially those with avant-garde sense of the designer, often claimed to abandon any tradition, that his work is not traditional, but the actual situation can not be so. Even the most "anti traditional" designers, it is necessary to "traditional" as the opposite of the reference object to define and interpret their own thinking. Design never is not a purely personal behavior, from the dominant tradition media, language and technique of expression. To design awareness of cultural mentality, thinking mode, aesthetic point of view such as hidden traditions are intentionally or unintentionally affects every interior designer.

The development of science and technology and the progress of the times make contemporary designers have the conditions that the predecessors did not have. The application of computers, the development of information, so that the design of the work has a stronger sense of the times. However, the richness of the works means can not replace people's sense of return, interior designers must be closely related to human from the utility to consider the work of the fine texture and warmth. We will create the indoor environment with elegant style, is bound to follow the "invisible elephant", "Da Yin Xi Sheng" creative way. Otherwise it is impossible to let the audience feel the corresponding aesthetic imagery. This "beauty" and "beauty" of the creation of the law, it is from China's thousands of years of traditional culture to extract. Therefore, it is an excellent designer should pay attention to the traditional culture into the modern design concept.

\section{The Essence of Chinese Traditional Culture and Its Application in Interior Design}

Chinese traditional culture in the course of its thousands of years of history, Confucianism, Buddhism, Taoism, three in the struggle, mutual integration, promote the prosperity and 
development of Chinese culture. Regardless of the historical or contemporary Chinese design works, all by its influence.

Confucian doctrine of the mean. The core idea of the doctrine of Confucius and Mencius is a middle course. First, attach importance to the Confucian philosophy of man and heaven "the person and the nature harmonious thinking mode and value orientation, and a Chinese designers with the design philosophy and constitutes the traditional Chinese design the basic philosophical connotation. Some brands of real estate interior design, attaches great importance to describe the nature, like heaven and earth, using human nature's intricate, reconstruction of the beauty of nature, and did not reveal as much as possible artificial chisels traces, achieve "although the people, like natural" harmony between human and nature, the unity of the heaven and the aesthetic realm. [2] Secondly, the Confucian doctrine of the mean, in the decorative culture has also been applied. For example, home, do not do any decoration, will appear simple, backward and no angry, and too much too vulgar. Just right of the decoration is pleasing to both the eye and the mind, both spiritual encouragement and conducive to physical and mental and correct attitude and desire to exercise restraint, do not do too much to expect, make the scene situation Aioi, community rise for spiritual realm.

Taoist elegant mystery. Laotse held that beauty in the Tao, and Tao nature in nature, that is, naturally, the so-called "imitation of nature", "Da Yin Xi Sheng, invisible elephant, Tao is hidden and unknown." Lao Tzu's "Tao" is the pleadings of the unknown void, not logic, reason, language can convey it beyond all the sense and language in the world, it rely on is not the language, but by super language image symbol system to achieve, so it has abstract and transcendent. The application of Taoism culture in interior design, mainly to enrich the interior space of Chinese architecture. In space to create many of the actual situation of Wai, such as each other alternately, sharing, such as doors and windows of the building, introduction of the indoor outdoor scenery; between interior space partition, decoration of a room introduced to another room to each other by means of the king, to strengthen the sense of space of flows, increased sense of openness. Another style of traditional culture of Taoism in the interior design is elegant, poetic creation camp, wenqi. The key to the construction of this kind of artistic conception space is to be able to introduce virtual static, introducing a peaceful state of mind. The traditional color techniques, simple elegance of the material and the traditional decorative visual symbols, entry into the feeling of entering, open taste, simple light, modest, quiet, sparsely long.

\section{Meditation in Buddhism}

Zen Buddhism is a Chinese Buddhist sect formed on the soil of Chinese culture because of the gradual eastward spread of Buddhist culture. It promotes the way of thinking through the individual's intuitive experience and meditation, so as to achieve spiritual freedom in the sense through the understanding of the environment. In the eyes of Zen, provisions of the smaller, imagine the greater room for, and thus less able to win, only a simple to the extreme, to set aside to maximize the space for people try to figure out thinking.

In recent years, in the classical and modern, Chinese and Western colored furniture, with Zen furniture uptake in the classical furniture of elegant and modern furniture simple, neat lines, pure colors, with rich Oriental means image, quite can create a quiet and comfortable home atmosphere. The Zen furniture material with walnut wood, camphor wood is in the majority, some of the desktop and then supplemented with glass, stone and other materials and in pottery dish placed some chayote, citrus. Dark wood with light cloth, leather, stone or glass furniture sells well, slightly calm but not significant old-fashioned style by the consumer favorite. [3] 
The existence of regional culture is a fact, take the building and indoor environment, Tibet, Xinjiang, Yunnan,...Protection and development of excellent regional culture is very necessary, only so, human culture can be colorful, not to mention the protection and development of the prosperity of the region's economy, tourism, etc. have a positive meaning.

The impact of regional culture is inevitable, the difference is only the intensity of the impact and sooner or later. Impact is not a bad thing, because, in a sense, the regional culture is in a variety of cultural collision, exchange and integration in the development.

More information developed in the era, more is in the period of reform and opening up, more is to facilitate contacts with the domain of regional culture by the impact of the more violent. In recent years, China's coastal areas, especially the impact of a strong, with the background of a relationship.

In recent years, in China and the various regional culture constitutes the impact of culture there are mainly two kinds: a kind is Outland culture, especially western culture; another is commercial culture. Take the building and indoor environment, "Euro Customs," Mediterranean style "forest" Roman colonnade "," semi-circular arch "," human sculpture ", popular, Outland culture menacing proof. Commercial culture is associated with economic restructuring and stronger, the competition of architecture and interior environment exists generally high bucket, contests, ostentatious and extravagant displays of wealth and the tendency, is the impact of the commercial culture reflect. Commercial culture is the core competition and to penetrate to the business. The construction industry is logical, is worrying, commercial culture is now clearly penetrate into administrative office buildings and residential buildings to, in recent years, many places regardless of the need and possibility, contend for building large squares, large office buildings. One of the reasons is affected by the impact of commercial culture; residential renovation "Hotel", "cabaret", and cultural and commercial penetration was revealed.

Interior design is an organic part of social culture, from the point of view of the horizontal dimension, no matter what kind of style design, have a specific mental and psychological structure of culture is in certain cultural context start and finish, and reflects the different value and aesthetic concepts, reflect the prevailing cultural outlook. From the longitudinal perspective, the design of the interior space of any era is closely related to the productivity and culture at that time. Design form comes from culture, people in accordance with the rich experience (history and tradition) of the processing of all the existing impression. In this sense, the design of history is the history of design. traditional culture affects the interior design. Although some modern designers, especially those with avant-garde sense of the designer, often claimed to abandon any tradition, that his work is not traditional, but the actual situation can not be so. Even the most "anti traditional" designers, it is necessary to "traditional" as the opposite of the reference object to define and interpret their own thinking. Design never is not a purely personal behavior, from the dominant tradition media, language and technique of expression. To design awareness of cultural mentality, thinking mode, aesthetic point of view such as hidden traditions are intentionally or unintentionally affects every interior designer. The development of science and technology and the progress of the times make contemporary designers have the conditions that the predecessors did not have. [4]The application of computers, the development of information, so that the design of the work has a stronger sense of the times. However, the richness of the works means can not replace people's sense of return, interior designers must be closely related to human from the utility to consider the work of the fine texture and warmth. We will create the indoor environment with elegant style, is bound to follow the "invisible elephant", "Da Yin Xi Sheng" creative way. Otherwise it is impossible to let the audience feel the corresponding aesthetic imagery. This "beauty" and "beauty" of the creation of the law, it is from China's thousands of years of traditional culture to extract. Therefore, it is an 
excellent designer should pay attention to the traditional culture into the modern design concept.

After the reform and opening up, the rapid development of interior design and decoration industry, but we are prepared in particular, the lack of talent preparation. So surrounded by flood, rush into battle some designers with the foreign pictorial as a treasure, and to imitate and copy as a shortcut, resulting in a "coastal sea copy of Hong Kong and Taiwan, the mainland copy coastal" a surprising phenomenon. The emergence of this phenomenon, rather than Outland culture and commercial culture violent impact performance, still be inferior to saying is the result of Outland culture and commercial culture to seize the opportunity to sneak in.

Imitation, copy phenomenon in interior design field, put forward sharp criticism of the profession already. But in the author's opinion, the appearance of this phenomenon is the historical necessity. The important thing is to seriously reflect on the lessons learned, as soon as possible to imitate and copy on behalf of the serious and serious creation.

Happily, in recent years, copy the Roman column, "Greek sculpture", the momentum has been greatly reduced, and there are a lot of mature designers to create a cultural connotation is deep and has regional characteristics of the masterpiece.

Culture has no national boundaries. In today's economic globalization and information technology developed, the culture of any countries and regions could not pure and pure, they can only be in the collision, exchange and integration of a variety of cultural development, showing a pluralistic situation. However, excellent regional culture, especially the excellent architectural culture and interior culture will not disappear.

The occurrence and development of Architectural Culture (including interior). Restricted by two factors: first, geographical factors, including topography, geomorphology, climate, resources, etc.; the two is the social factors, including political, economic, ideological, religious beliefs and ways of life, etc..

It is also difficult to affect the development of architectural culture at once. Social factors change is relatively sensitive, take our country, since the reform and opening up, people's thinking has been a great change. However, even the relatively sensitive social factors, there are some more stable parts, such as religious beliefs, aesthetic values, etc. From this, the regional architectural culture can not completely disappear. Moreover, knowledgeable designers are also on the excellent part of the protection and development. In the case of Tibetan Diaolou, the window is small, the top flat, wall thickness and width of narrow features. This is by the Tibet Plateau, strong solar radiation, drought little rain, Shi Shao wood and other natural conditions decide. As for the interior layout and color and decorative patterns and so on by the influence of Tibetan Buddhist culture. Undeniable, in future years, Tibetan Diaolou will change that, but geography and religion will long-term infiltration to Tibet's architectural and that Tibetan Architecture and indoor environment will still have distinct regional.

For more than 20 years of interior design practice, we provide a number of experience and lessons, one of the most important is the need to comprehensively improve the quality of design personnel, and in these qualities. Cultural and historical knowledge is very important. Otherwise, and vigorously promote the "Roman colonnades" will not "Roman column" how kind; and vigorously promote the "Chinese design", in addition to the red column, palace lantern, it is also difficult to say clear "Chinese design" what is. If you want to create a modern interior environment with Chinese characteristics, we must first understand the development process and characteristics of traditional Chinese architecture interior design and decoration, and draw lessons from the experience.

Chinese traditional architecture do have many features and advantages. First, pay attention to the 
relevance of the internal and external environment, coordinated with the local natural conditions and external landscape, this just take a look at the types and characteristics of the Chinese traditional architecture, such as tower, pavilion, pavilion, gallery, terrace has been quite clear.

Second, flexible interior space organization, consists of rich levels, and the resulting many unique Geshan, cover, screen, curtain, Babolat lattice space dividers.

Third, pay attention to the status and function of furniture and furnishings in the environment. Pay attention to the connotation of exquisite grade many furnishings such as calligraphy, painting, carving screen, inscribed boards, couplets, stones and bonsai etc. are endemic to China and foreign countries have little or no the. [5]These are the furniture and furnishings with the indoor environment with rich cultural connotation also tend to a regional value.

Fourth, reflecting the high degree of unity of architectural technology and architectural principles. The brackets, painting, QT, April beam, Geshan, shelf no one does not have this unity. Only later, only some brackets lost structural meaning and become a pure decoration. Fifth, more subtle techniques, commonly used symbol and metaphor, let people can enjoy the "buzzing" and "memorable". The characteristics and advantages of the Chinese traditional architecture in interior design and decoration is far more than the five point, however, is that this is enough to prove that the characteristics and advantages of Chinese interior design and decoration, not only in the form of, but the very rich technique, principle and concept. It is these practices, principles and ideas, to create a modern interior environment with Chinese characteristics, has a valuable significance and value.

If you want to create a modern indoor environment with regional characteristics, but also a profound understanding of the culture of the region. Take Guangzhou for example, whether it is geographical factors, or social factors, there are many different things from other regions. Wide, Dongshan arcade, Xiguan patio is not an accident of, the design of the last century built the White Swan Hotel, Dongfang Hotel, friendship theatre so successful, so it has many experience is worth to draw lessons from, but also because they take full account of the natural conditions in the south of the five ridges and reflects the regional culture's sake.

If you want to create a regional characteristics of modern indoor environment, naturally to seriously study the culture of Outland, and earnestly learn from the good part. Chinese culture and Guangzhou culture since ancient times, mastery of the merits. In the interior design of an unprecedented active today, of course, should not reject all advanced things. To do this, to seriously study, otherwise it will continue to stay alive, read hastily and without thinking level.

The interior designers of Japan and South Korea have actively explored and accumulated valuable experience in the area of cultural and cultural aspects. Let's make a brief analysis of the following items.

Tokyo is a new national theater, opera, ballet, drama of cultural institutions, and it was the first National Theatre built in Japan. The theater stage device, the internal facilities are very advanced, but the architectural design and interior design has clearly retained traces of traditional Japanese culture. The theater theater table and chair were to wood as the main material, proscenium two barium u well grid modeling could not help but make are reminiscent of the residential push and pull the door, based on the acoustic design of pick Taiwan Craft precise, fully demonstrated the Japanese Seiko fine, pay attention to the details of the traditional. The theater is an outdoor garden, is a communication inside and outside environment of space, it atmosphere of calm, pure and beautiful, and traditional Japanese House garden and temple garden has many of the shape and spirit.

Seoul, South Korea, an important intangible cultural heritage hall with performances, learning, 
exhibition, office, rest and other functions of a variety of skills. In the vertical design of the designer uses many rich ethnic characteristics of the technique, in the interior design, on the one hand introduced a range of advanced facilities, strengthening information transmission function space and flexibility of the concept of space, on the one hand and strengthen the environment of local flavor, theatre of smallpox, railings, partition is simple, light, room atmosphere and simple, clean, open, stability, and Korean traditional style come down in one continuous line.

How to design a hospital, there is a concept of the problem. The interior design of the Bucheon Hospital of Hyang soonchun University in Korea provides us with beneficial enlightenment. His design philosophy is: comfortable family room; no mechanical impression in the operating room, culture and natural atmosphere of furnishings mood letting a person is quiet space environment. (see Figure 7 page 3) is a corner of the hospital waiting room. (see Figure 8, page 3) said the hospital ward. From these pictures, it is not difficult to specifically feel the basic concept of the designers, it is not difficult to feel the designer reflects the efforts of local culture. These are the environment, from different perspectives reflect the characteristics of Korean architecture inherent calm, simple, introverted, unassuming.

Japan and South Korea are more advanced economic and technological countries, but they are also very importance to the national tradition and the local culture of the country. Their experience and our designers have accumulated experience is worth careful summary.

After nearly twenty years of practice and exploration. China's interior designers have been gradually mature from the exploration and reflection, there is reason to believe that China's interior design will soon enter a new stage, to a new level.

\section{Inherit the Traditional Culture of Interior Design Method}

The development of the times has its basic context, the need to design a new soul and blood. Therefore, it is necessary to integrate the traditional and modern aesthetics and design ideas into the design.

The use of traditional symbols. China's traditional symbols are: traditional symbol and figurative meaning of the patterns and patterns; ancient traditional totem decoration; traditional religious symbols. These traditional symbols, some predecessors in the production of labor, the construction of the residence of the experience and wisdom of the accumulation, and some are the pursuit of spiritual life and reflect. In modern times, these symbols still have a positive practical significance, the direct use of these traditional symbols as decorative elements, is to create a traditional culture of the interior environment of the effective way. General approach: abstract this technique is simple, the whole of traditional form or local art processing, refined and simplified, its principle is to lose the traditional shape without losing the traditional rhyme, so that a certain cultural tradition of Confucianism, Taoism and Buddhism in, on the basis of the function and technology of modern on the continuation and development; symbolic collage, its characteristic is the traditional component familiar to abstraction, cracking or deformation, making some typical or symbolic signs, and in the interior elements of collage in use, so that the new and old, ancient and present with a link transplantation and transplantation; grafting, grafting of Confucianism, Taoism and Buddhism History and culture, make it become a kind of new artistic image. In the design, sometimes we can use some of the elements of foreign culture and local cultural elements were born in one.

Color and light treatment. Color through the visual effect on the psychological, often affect people's emotions, people's spirit and behavior. Color itself is not absolutely beautiful or not beautiful, but the interior space of the color collocation is very important. Color processing 
techniques: one similar to the color, namely the hue ring not far from the adjacent colors, such as yellow and orange, purple and purple, blue and purple and green (green). Similar to each other close to each other, and a slight change of unity. Second, color contrast is two far to match the color harmony, it is often said that the "complementary principle", red flowers and green leaves more beautiful. This is because the two are mutual complementary sake. And light and shade is another way of rendering color, light and shadow.

The existence is always in the presence of a specific color vector. Light and shadow in the interior space is also a direct or auxiliary to convey the traditional information of the effective elements and tools. Color has a significant role in changing the atmosphere of the environment, especially in the light of the common role of light and shadow to create a different space atmosphere and artistic conception.

Space and furniture furnishings return to nature. Harmony between man and nature is a harmonious relationship between man and nature, that is, the harmonious relationship between man and nature. Although Confucianism, Taoism and Buddhism and traditional culture characteristics are different, but in return to nature and follow the natural, but in common. However, in the tension of urban life, the desire to be close to nature can not be achieved. Therefore, empathy in the "home", and strive to create a natural atmosphere as a spiritual compensation, to achieve a sense of return.

Interior design regression natural means mainly: one is to create a space, such as skillfully processing natural part of the limited indoor space blend with the outside world, in the face of Castle Peak window, or blue and fields become porch design background and ability to borrow scene; in addition, you can also work in the choice of decoration materials.

Rough rock wall or gypsum board imitation stone material, give a person a kind of natural flavor reversion. Dry corn; second, furnishings, such as indoor display some of the original exotic decorations, increase the natural artistic conception through red or golden string, or a bundle of dried wheat, white reed catkins, and handmade batik cloth, and so on, clever embellishment, ingenuity alone, will achieve an unexpected natural beauty effect, or on the wall, hanging or draw some pictures, is a piece of lakes, a forest, or the endless wilderness, bamboo, before painting with some and the coordination of potted plants, combined with the actual situation, will make people feel fresh and comfortable, open field of vision, I walked into the natural feeling. As a designer in China should be based on reality, a serious look at the history and culture of the Chinese nation, duty bound to carry forward and inheritance of traditional culture, the modern art design with the closer together, the formation of modern and traditional combination of interior design style.

The Exterior Wall Coating. Coating is the liquid material generally refers to the composition of adhesive, coating liquid of additives and pigment directly connected with the object surface. Application of coating is very extensive, often used for building external walls, floor, ceiling, roof waterproofing, etc. The biggest characteristic of exterior wall coating is that it can well reflect the variation of the building blocks, can create the seamless effect in widespread. At the same time it can provide us with the abundant optional colors, the cost and construction technical requirements are relatively low. Because itself doesn't provide too much visual details, when take that in design, we should be deliberate about the block combination, color contrast.

In the design, you can use a single color of paint and also use a variety of color combinations, single white coating can reduce the visual component of the outer wall material, purify the visual, can produce the feeling of pure and elegant aesthetic. White as the background, it can set out the details of the surroundings really. A large area of black can present a deep, mysterious visual effect, Because the contrast for light and dark is weak, usually it can hide some deficient details. Black used in large should pay attention to avoid the atmosphere of dreary and depressing. We can 
through the transparent glass material , local bright way to transfigure. A large area of grey paint can create soft artistic visual effect between white and black. Different color coating can create abundant visual effect. Many design success by the combination of the building blocks, coating colorific.

Water Concrete. The boomy of water Concrete is the period of the modernism architecture flourished, purely functional, economic, construction technology, ascribe to the same concrete building form., lacking of details. The result would be different if take design into concrete. Natural and optional.

Since the 1970 s. Famous Japanese architect Tadao ando was well known for his distinctive lighting design, delicate and elegant detail, strong sense of collection, the profound eastern philosophy. Among his works, concrete has become its landmark building materials, his works often shows exquisite texture of mechanical processing, letting more designer rediscovering the endless charm of the concrete. Then there rise the "concrete" hot. At the same time, the abuse of industrialization stylized unification of glass curtain wall, stone, brick in building decoration also makes people have a rebellious attitude. Natural, simple design style has become goals that people pursuit of. So that concrete has some new markets.

Different design pursuit different use of concrete, some people pursuit exquisite, strive to express the feeling of elegance .Some pursuit the rough strength feeling, keeping the traces of construction, pay attention to the authenticity of the performance. Another is the combination for rough and exquisite, making the structure looks elegant from overall, but powerful and rugged from close.

Ceramic Bricks. For the pursuit of traditional beautiful craft, and in addition, in order to meet the requirement about light and thin which represent modern decoration materials ,then the new material appeared.

In our country, brick used for exterior wall often paste by artificial workers. The advantage is construct convenient, especially for the lower and rich region for human cost. The disadvantage is that they can't guarantee the brick paste craft, what's more, long time soaking by rain and ruin by winter freeze-thaw hide safety trouble. In Japan, the most common method is to place and pouring the brick on concrete structure beforehand, therefore, tile and brick joint is closely and not easy to fall off the back.. This construction craft demanding high technology. As in the recent years advocates the spirit of environmental protection and energy saving in domestic, there appear the way factory paste the external tile on insulation board. [6]Then put the finished plate fixed on the wall. Most of the brick has good durability, self-cleaning ,corrosion resistance, etc, at the same time the price is relatively cheap, so it is easy to find in domestic use ceramic bricks both inside and outside wall.

Anticorrosive Wood Materials. The advantage of lumber can give a person sense of natural warm, both feel better in look and feel. But its shortcoming is weather resistance, durability. Hard to maintenance. Therefore, we rarely find it's decorate as external material directly. However, the research and development of new materials handled this problem. Adopting preservative treatment of wood (vacuum pressure, atmospheric soaking, spraying method), prolong the service life of its use in the outdoor environment, combined with the reasonable use and maintenance, ,some outdoor wood now can reach more than 20 years or 30 to 40 years of life.

In recent years, in China and the various regional culture constitutes the impact of culture there are mainly two kinds: a kind is Outland culture, especially western culture; another is commercial culture. Take the building and indoor environment, "Euro Customs," Mediterranean style "forest" Roman colonnade "," semi-circular arch "," human sculpture ", popular, Outland culture menacing proof. Commercial culture is associated with economic restructuring and stronger, the competition 
of architecture and interior environment exists generally high bucket, contests, ostentatious and extravagant displays of wealth and the tendency, is the impact of the commercial culture reflect. Commercial culture is the core competition and to penetrate to the business. The construction industry is logical, is worrying, commercial culture is now clearly penetrate into administrative office buildings and residential buildings to, in recent years, many places regardless of the need and possibility, contend for building large squares, large office buildings. One of the reasons is affected by the impact of commercial culture; residential renovation "Hotel", "cabaret", and cultural and commercial penetration was revealed.

Stone Walls. Laying stones, the using of stone material just like laying brick masonry together, mainly through their weighing, generally applied in design for thicker wall which is not very high. We common lay pebble, not only aesthetically pleasing, and natural. At the same time also reflect a certain local cultural characteristics.

\section{References}

[1] Interior Decoration Materials, Cai Shaoxiang ,Chemical Industry Press, 2010-9-1

[2] 21st Ccentury Institutions of Hhigher Learning , Interior Decoration Materials and Cconstruction , Chen Xuejie , China Electric Power Press, 2009-4-1

[3] Interior Decoration Materials and Construct tutorial, The National Higher Vocational Education of Art Design Professional, Zhangqian, Investigation Southwest Normal University Press, 2007-5-1

[4]Interior Decoration Materials in Colleges and Universities, Zhang Qqiumei ,Xiang Shilong, Zhang Qiuhui, China Forestry Publishing House ,2003-4-1

[5] Interior Decoration Materials,Guo Hongwu, Water Conservancy and Hydropower Press, 2013-7-1

[6] The Construction of Interior Decoration Materials , Chen Xuejie, Industry Summit People's Posts and Telecommunications Publishing House 2013-6-1 